\title{
Green Approach for Synthesis of Manganese Nanoparticle using Banana Peel (Musa paradiasca) and its Characterization
}

\author{
Sharmila Pradhan Amatya ${ }^{1,2 *}$, Santu Shrestha ${ }^{1}$, Yadav Aryal ${ }^{1}$ \\ ${ }^{1}$ Department of Chemistry Amrit Campus, Tribhuvan University, Kathmandu, Nepal \\ ${ }^{2}$ Nepal Polymer Institute, Kirtipur, Nepal \\ *Email: sharmilapradhan23@gmail.com
}

(Received:6 March 2021, Received in revised form: 20 April, Accepted: 28 June 2021, Available Online)

\section{Highlights}

- Multifunctional manganese nanoparticle was synthesized using banana peel as the reducer and stabilizer.

- As synthesized samples were characterized spectroscopically via UV-vis, EDX, XRD and FT-IR.

- UV-absorption peak observed at $450 \mathrm{~nm}$ confirmed for the formation of manganese nanoparticles.

- Diffraction pattern revealed formation of crystalline natured nanoparticles.

\begin{abstract}
This research mainly aims at implementing green approach for synthesizing multifunctional manganese nanoparticles (MnNPs) using aqueous extract of banana peel (Musa paradiasca) and potassium permanganate (KMnO $)$ as the precursor. As synthesized MnNPs were confirmed initially by color change and later on characterized by UV-visible (UV-vis) Spectrophotometer, Energy Dispersive Spectroscopy (EDX), X-ray Diffraction Spectroscopy (XRD) and Fourier Transform Infrared Spectroscopy (FT-IR). Green approach was carried at various parameters like concentration of precursor solution, reaction time, temperature etc for optimization. Formation of MnNPs was confirmed by the presence of surface plasmon absorbance band (450 nm) and band at 6 and $6.5 \mathrm{keV}$ of EDX spectrum. Likewise, so formed MnNPs were crystalline nature depicted from the sharp peak observed at $28.5^{\circ}$ and $41^{\circ}$ in X-ray diffraction pattern. Various types of biomolecules associated with the banana peel extract acting as natural reducer and stabilizer were analyzed from characteristic absorption bands present in the FT-IR spectrum.
\end{abstract}

Keywords: Diffraction pattern, Musa paradiasca, MnNPs, Precursor, Spectroscopy.

\section{Introduction}

In recent years, the green approach has been given a great consideration for producing a substantial amount of nanoparticles, and for environmentally nature [1-3]. Green approach seemed to be based on three essentials parameters such as a) reductants, b) stabilizer, and c) solvent [4]. Literatures revealed that various types of secondary metabolites such as terpenoids, glycosides, polyschharides, polyhydroxyphenols, alkaloids, flavonoids, phenolics, proteins are crucial reducing and stabilizing agents [5]. The green route of fabrication of nanoparticles (NPs) uses various plant parts root, leaf, stem, bark, flower, microbes etc. For instance, the silver nanoparticles synthesized from Manilkara hexandra stem bark were found in the range of 15-50 nm size [2], [6-8]. Similarly, Momosa pudica and Rhyza stricta root extract were used as natural reducing and the stabilizing agents [9 -10].

Various kinds of metal nanoparticles like gold, silver, platinum, iron, copper, manganese, zinc, iron, etc were exploited in diverse sectors from time immemorial [11-22]. In this scenario, MnNPs are considered promising materials for their outstanding physiochemical properties such as adsorbing, electrochemical, catalytic, magnetic, medicinal, bactericidal etc. Consequently,

${ }^{*}$ Corresponding author 
environment, catalytic, bio sensors, energy storage, magnetic resonance imaging, lithium ion batteries, biomedicine, drug delivery, etc are regarded as potential existing sectors for their application [23-27].

Hence, the objective of this research is to fabricate multifunctional manganese nanoparticles based on the green approach utilizing banana (Musa paradisica) peel extract (BPE) and to characterize them using various spectroscopic techniques. During the reaction, various types of phytoconstituents present in the banana peels were hypothesized to act as reducing and stabilizing agent [28].

\section{Materials and Methods}

\section{Materials}

Banana peels (collected from the local market of Kathmandu), potassium permanganate $\left(\mathrm{KMnO}_{4}\right.$ A. R. grade) and distilled water were used.

\section{Preparation of banana peel extract}

Firstly, the banana peels were washed with distilled water for three times to remove external dirt impurities and then cut into small pieces. Then, about $100 \mathrm{~g}$ of peels were allowed to boil at $80^{\circ} \mathrm{C}$ in $500 \mathrm{~mL}$ beaker containing double distilled water for 10 minutes and filtered through filter paper twice to remove insoluble fractions and macromolecules. The resultant filtrate was stored at $4{ }^{\circ} \mathrm{C}$ and used as the banana peel extract (BPE) for green synthesis of MnNPs.

\section{Green synthesis of manganese nanoparticles}

Firstly, potassium permanganate of different concentrations: $1 \mathrm{mM}, 2 \mathrm{mM}, 3 \mathrm{mM}, 4 \mathrm{mM}$ and $5 \mathrm{mM}$ were prepared so as to optimize the concentration for synthesis. Each of the precursor solutions were reacted with aqueous banana peel extract at 1:5 volume ratio (peel extract and $\mathrm{KMnO}_{4}$ ) in a beaker using the protocol of literature [23]. The mixture was allowed to stir constantly using magnetic stirrer at $30-40{ }^{\circ} \mathrm{C}$ till the color changed to reddish black as the color change was the indicator of the formation of MnNPs. As-synthesized MnNPs were then purified by repeated washing and centrifugation. Finally, MnNPs were collected after oven dried at $40-50{ }^{\circ} \mathrm{C}$ and then subjected for various spectroscopic techniques.

\section{Characterization techniques}

As-synthesized MnNPs were characterized using double beam UV-vis spectrophotometer (Model LT-2802) in the wavelength range 200-700 nm, at $5 \mathrm{~nm}$ interval. Phase morphology of the banana peel mediated MnNPs was explored using X-ray diffraction (BUKER D2 PHASER, NAST) having CuK $\alpha$ radiation and Braggs angle (2 $\theta)$ in the range of $5^{\circ}$ to $90^{\circ}$. The crystalline size of the MnNPs was calculated by using Debye-Scherrer's equation,

$$
D=K \lambda / \beta \cos \theta
$$

Where, $\mathrm{D}$ (particle size), $\mathrm{K}$ (factor $=0.94), \lambda($ emission wavelength $=1.54 \AA)), \beta$ (Full width half maximum $(\mathrm{FWHM}), \theta$ (Bragg's angle)

The energy dispersive X-ray spectroscopy of model EDX-8000 was used to study the elemental composition of the sample. For the identification of functional group associated with the organic biomolecules of the BPE, Fourier Transform Infrared Spectroscopy (FT-IR) Tracer 100 was used in ATR mode in the range of $400-4000 \mathrm{~cm}^{-1}$ with a resolution of $4 \mathrm{~cm}^{-1}$.

\section{Results and Discussion}

\section{Visual inspection}

Firstly, the appearance of reddish black color on stirring the reacting solutions for 15 minutes inferred about the presence of nanoparticles. The color change attributes for the reduction of $\mathrm{KMnO}_{4}$ from biomolecules of the extract [29-30].

\section{UV-vis spectroscopy}

The UV- vis spectrum of biosynthesized MnNPs using BPE and $\mathrm{KMnO}_{4}(3 \mathrm{mM})$ (Fig.1) clearly displayed a maximum 
absorption at $450 \mathrm{~nm}$ which attributes to the surface plasmon resonance of electrons present at the surface of nanoparticle. The reported wavelength of maximum absorbance is slightly higher than that of literature [23], [31] which may be due to difference in $g$

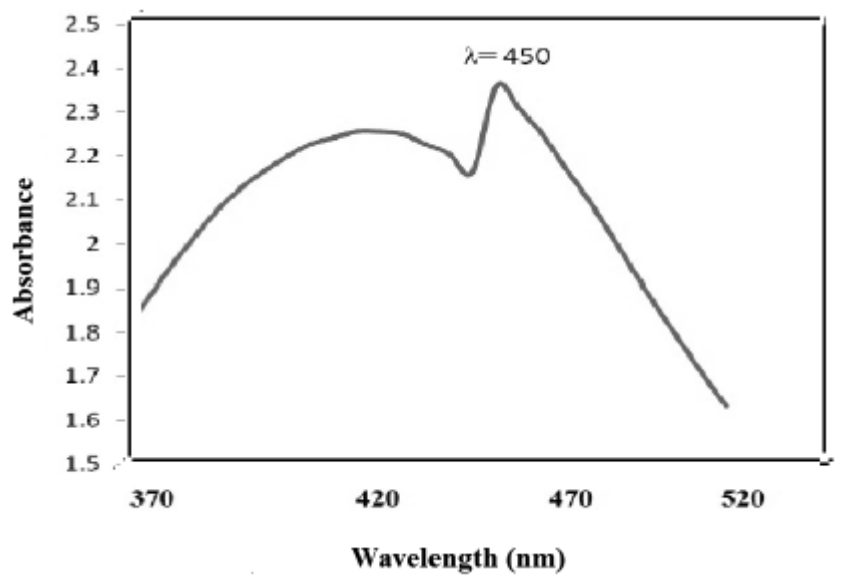

Fig 1: UV-vis spectrum of biosynthesized MnNPs, using aqueous extract with $\mathrm{KMnO}_{4}$ at volume ratio 1:5

From the literatures, distinct UV-vis absorption band in the spectrum indicates presence of smaller sized, nanoparticles [32]. Similarly, the absorption band with single and double peaks indicates the presence of spherical and ellipsoidal nanoparticles. [29]. Formation of the single peak in the UV-vis spectrum inferred about the formation of spherical MnNPs. For the confirmation, it needs to be analyzed by using scanning electron microscope (SEM) and transmission electron microscope (TEM).

\section{Optimization of concentration of precursor $\left(\mathrm{KMnO}_{4}\right)$}

Biosynthesis of MnNPs was performed varying the concentration of the $\mathrm{KMnO}_{4} ; 1 \mathrm{mM}$ to $5 \mathrm{mM}$ with volume ratio 1: 5 (BPE: $\mathrm{KMnO}_{4}$ ) keeping other parameters (like time, temperature) constant. Fig. 2 presents the UV-vis absorbance bands at concentration variation from $1 \mathrm{mM}$ to $5 \mathrm{mM}$. All of the curves depict peaks at $450 \mathrm{~nm}$, the assigned peak of the MnNPs as mentioned before. The Fig. 2 depicts that the absorbance increases with increasing the concentration of the precursor $\left(\mathrm{KMnO}_{4}\right.$ from $1 \mathrm{mM}$ (curve a) to $3 \mathrm{mM}$ (curve c) due to formation of larger amount of MnNPs. But, upon increasing the concentration beyond $3 \mathrm{mM}$ the intensity of absorbance decreases slightly (curve $\mathrm{d} \& \mathrm{e}$ ) due to formation of agglomeration of nanoparticles [33]. As the considerable amount of MnNPs are formed by $3 \mathrm{mM} \mathrm{KMnO}_{4}$ solution with respect to others, it is assumed to be optimized concentration for synthesis of MnNPs.

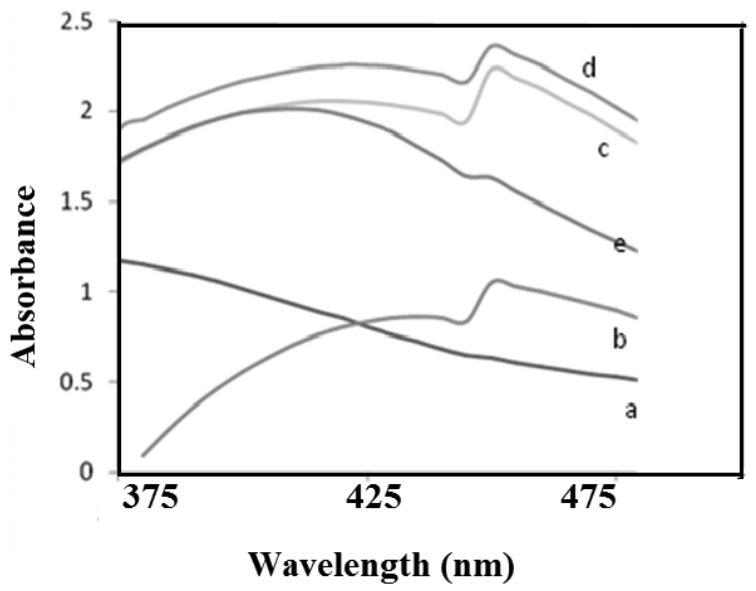

Fig 2: UV-visible spectra of MnNPs at different concentration of $\mathrm{KMnO}_{4}$ solution; (a) $1 \mathrm{mM}$, (b) $2 \mathrm{mM}$, (c) $3 \mathrm{mM}$., d) $4 \mathrm{mM}$ and e) $5 \mathrm{mM}$

\section{Optimization of time}

The aqueous banana peel extract (BPE) and precursor solution $(3 \mathrm{mM})$ at volume ratio $1: 5$ were stirred at $40{ }^{\circ} \mathrm{C}$ for different 
time intervals like 15, 25, 35, $55 \& 65$ min for optimization of the time. The absorption spectra of as synthesized MnNPs with time variation (Fig. 3) shows that intensity of maximum absorbance of MnNPs gradually decreases with time; the peak intensity of MnNPs at 15 minutes (curve a) is greater with respect to other samples; $25 \mathrm{~min}$ (b), $35 \mathrm{~min}$ (c), $45 \mathrm{~min}$ (d), $55 \mathrm{~min}$ (e) \& $65 \mathrm{~min}$ (f). The formation of considerable amount of NPs at initial 15 minutes attributes to the existence of large amount of reductants. The Fig. also indicates no significant change in size of NPs with times [30], [34-35]. The UV-vis result indicates optimized time as 15 minutes for the biosynthesis.

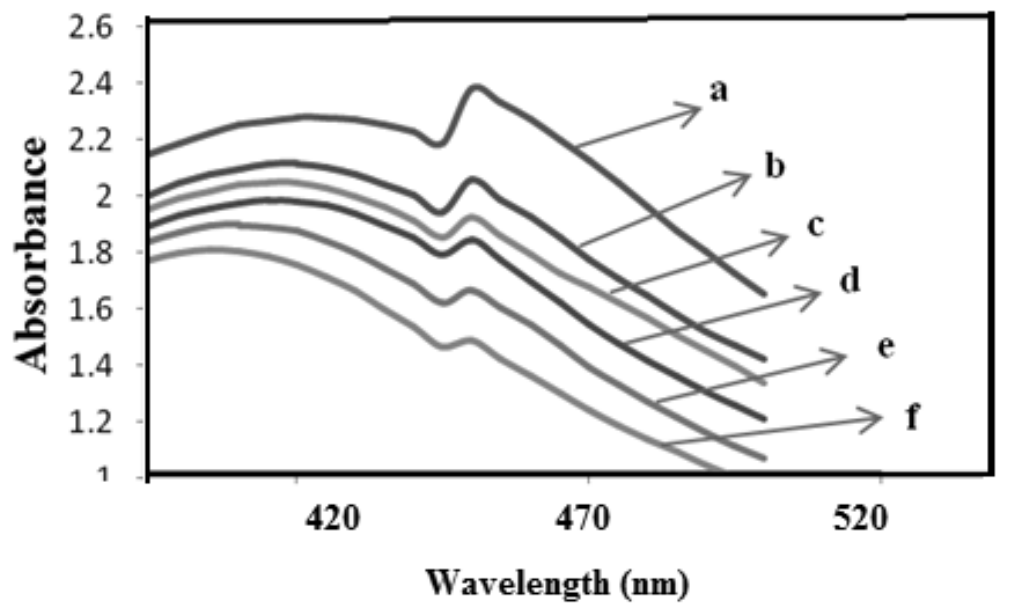

Fig 3:UV-Visible spectra of MnNPs at different time interval at (a) $15 \mathrm{~min}$, (b) $25 \mathrm{~min}$, (c) $35 \mathrm{~min}$, (d) $45 \mathrm{~min}$, (e) $55 \mathrm{~min}$ and (f) $65 \mathrm{~min}$.

\section{Optimization of temperature}

Fig. 4, the UV-vis spectrum of temperature variation shows that maximum absorption bands are not so significantly changed. The absorption bands of MnNPs at $20{ }^{\circ} \mathrm{C} \& 40{ }^{\circ} \mathrm{C}$ appeared at $450 \mathrm{~nm}$, (curve a \& c) and that of $30{ }^{\circ} \mathrm{C}$ is at $455 \mathrm{~nm}($ curve b). However, the peak of MnNPs at $30^{\circ} \mathrm{C}$ (b) is slightly shifted from (a) \& (c) which attributes to the formation of slightly bigger sized nanoparticles [23]. The result revealed that biosynthesis can be carried out conveniently at temperatures from $20{ }^{\circ} \mathrm{C}$ to 40 ${ }^{\circ} \mathrm{C}$ as the assigned peak of MnNPs are appeared at all temperatures.

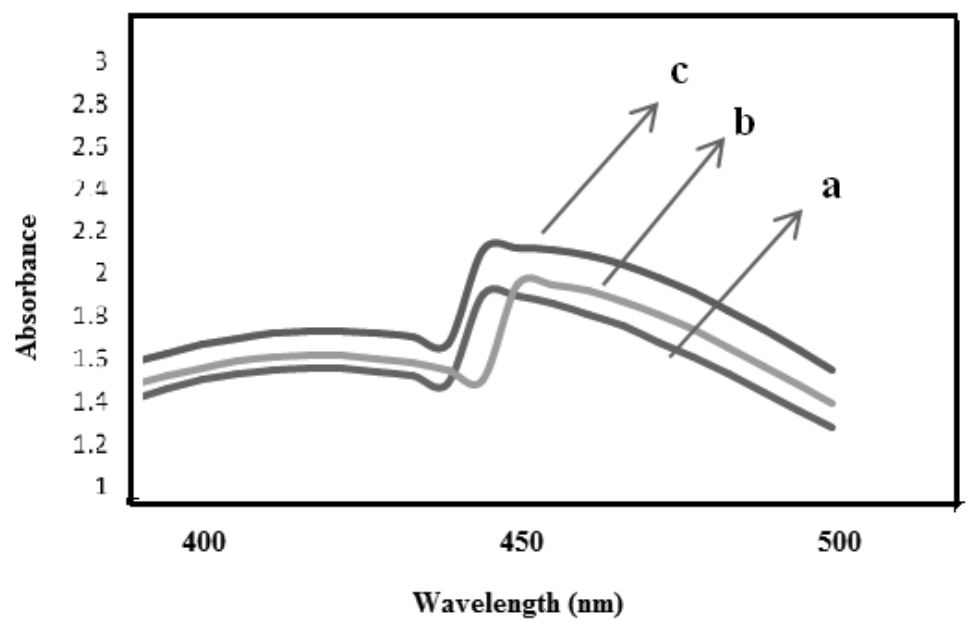

Fig 4: UV-visible spectra of MnNPs at different temperature (a) $20^{\circ} \mathrm{C}$, (b) $30^{\circ} \mathrm{C}$ and (c) $40^{\circ} \mathrm{C}$

\section{Energy Dispersive X-ray Spectroscopy (EDX)}

As-synthesized MnNPs was analyzed by using EDX spectroscopy for elemental composition and purity. EDX pattern (Fig. 
5) clearly displays the energy absorption bands at 6 and $6.5 \mathrm{keV}$ indicating the presence of manganese as in the literature [36]. Additionally, the EDX spectrum indicates the presence of $76 \%$ of Mn by weight (Fig. 5) along with other elements like $\mathrm{K}, \mathrm{Cl}, \mathrm{Si}$, $\mathrm{Ca}, \mathrm{P}, \mathrm{Zn}$, etc as impurities which may arise from sampling process.
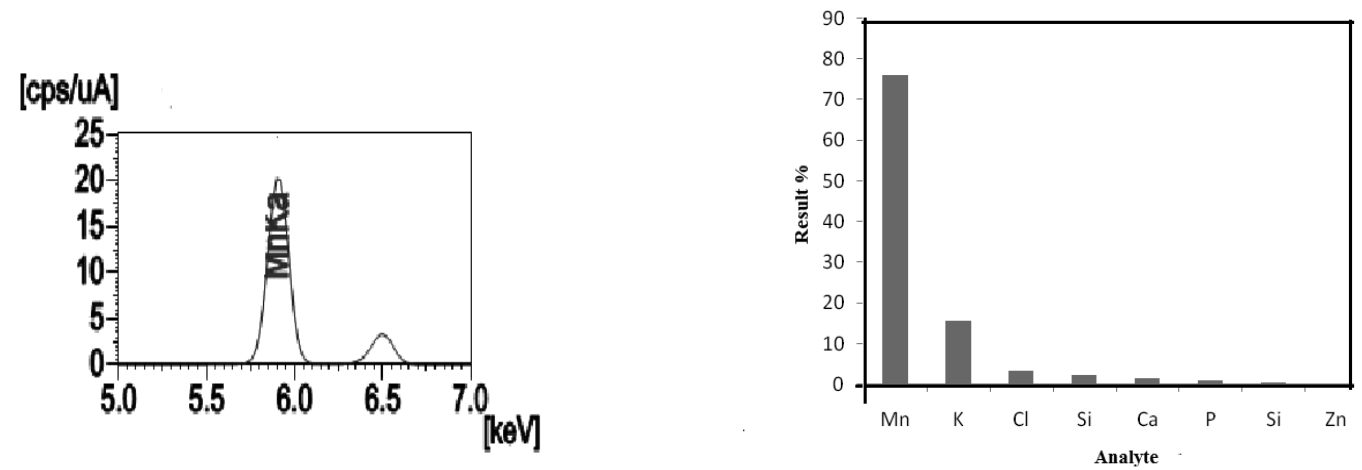

Fig 5: a) EDX Spectrum of biosynthesized MnNPs using aqueous BPE and $3 m M \mathrm{KMnO}_{4}$; b) Quantitative analysis of elements

\section{X-Ray Diffraction (XRD) Spectroscopy}

The XRD is basically used to study the phase morphology of the NPs. Diffraction pattern of banana peel mediated synthesized MnNPs is presented in Fig. 6. Diffraction pattern comprise of two broad peaks at diffraction angles (2Ө) $28.5^{\circ} \& 41^{\circ}$ which are indexed to face centered cubic manganese nanoparticles following the JCPDS No. 4-0326 as revealed in the literature [29]. Consequence of the XRD result confirmed for the formation of crystalline manganese nanoparticle. The crystallite size estimated to be $8.92 \AA(\sim 1 \mathrm{~nm})$. Broad natured diffraction pattern owes to the formation of small sized nanoparticles and biosurfactant associated at the surface of NPs as revealed by [36].

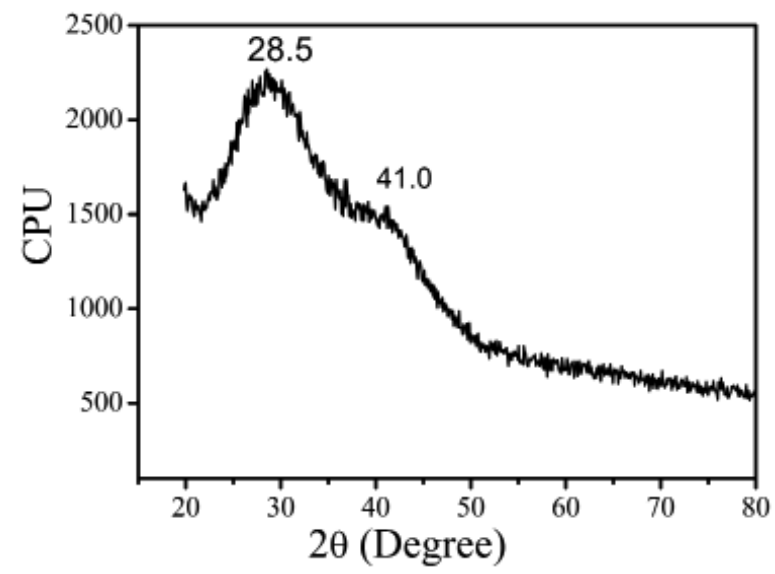

Fig 6: Diffraction pattern of biosynthesized MnNPs using BPE and $3 \mathrm{mM} \mathrm{KMnO}_{4}$ (Vol. ratio 1:5)

\section{Fourier Transform Infrared Spectroscopy (FT-IR)}

The FT-IR spectrum of MnNPs (Fig. 7) shows the broad peak around $3240 \mathrm{~cm}^{-1}$ attributing for -OH bending vibration of polyphenolic groups present in banana peel extract as reported by literature [23]. Likewise, absorption bands at $2885 \mathrm{~cm}^{-1}$ indicate $\mathrm{C}-\mathrm{H}$ stretching [32], $1646 \mathrm{~cm}^{-1}$ refers to $\mathrm{C}=\mathrm{C}$ and $\mathrm{C}=\mathrm{O}$ stretching vibration [37- 38]. Bands $1395 \mathrm{~cm}^{-1}$ and 1014 $\mathrm{cm}^{-1}$ represents $\mathrm{C}=\mathrm{O}$ stretch of amide and $\mathrm{C}-\mathrm{O}-\mathrm{C}$ stretching, respectively [23]. Banana peels are mainly composed of pectin, cellulose and hemicelluloses. Thus FTIR spectrum confirmed that the presence of various biopolymers along with proteinaceous compounds at the surface of MnNPs which act as reducing and stabilizing agent during biosynthesis of MnNPs [39]. 


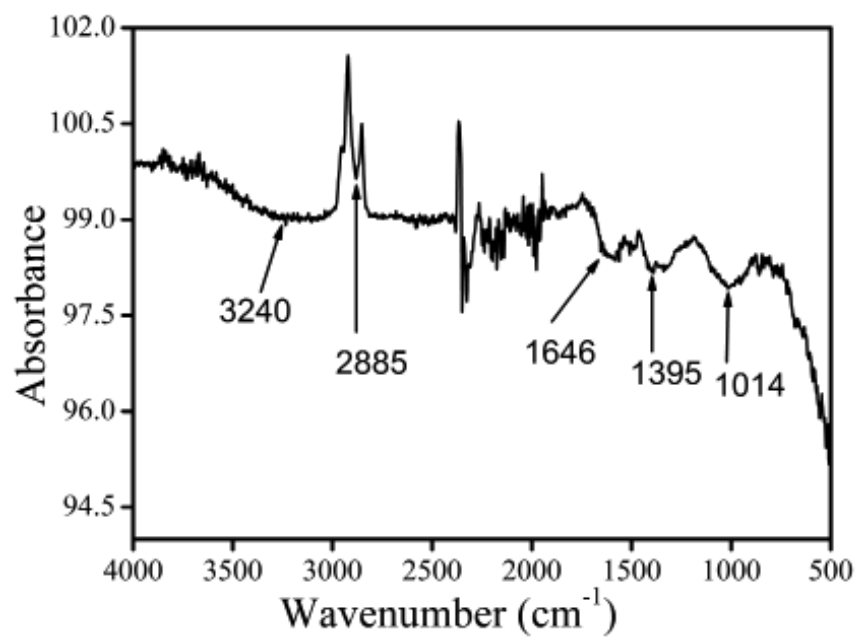

Fig 7: Fourier Transform Infrared (FT-IR) spectrum of biosynthesized MnNPs using peel extract

\section{Conclusions}

Manganese nanoparticles were successfully synthesized from eco-friendly and low cost green approach using aqueous banana peel extract. Formation of reddish brown colored precipitate provided the preliminary evidence of formation of MnNPs. Results of UV-vis spectroscopy confirmed the fabrication of manganese nanoparticles providing the assigned absorption band of MnNP at $450 \mathrm{~nm}$. Further, presence of Mn of $65 \%$ by weight in the as-synthesized sample was confirmed from strong energy absorption band at 6 and $6.5 \mathrm{keV}$ of the EDX spectrum. Result of X-ray diffraction revealed formation of crystalline nature manganese nanoparticles possessing the crystallite size of about $8.92 \AA(\sim 1 \mathrm{~nm})$. Similarly, various absorption bands appeared in FT-IR spectrum suggested for the presence of non toxic biomolecules which showed crucial role of reducing and stabilizing agent during the fabrication of manganese nanoparticles. Size controlled synthesis of MnNPs and exploration of catalytic properties of MnNPs can be the interesting research topic for future.

\section{Acknowledgements}

The authors would like to acknowledge the Department of Chemistry, Amrit Campus for the laboratory support .

\section{References}

1. M. Rafique, I. Sadaf, M. S. Rafique,M. B. Tahir. A Review on Green Synthesis of Silver Nanoparticles and Their Applications, Artificial Cells, Nanomedicine, and Biotechnology, 2017, 45(7), 1272-1291. (DOI:10.1080/21691401.20 16.1241792).

2. D. Gupta, and P. Chauhan, Green Synthesis of Silver Nanoparticles Involving Extract of Plants of Different Taxonomic Groups, Journal of Nanomedicine Research, 2017, 5(2), 1-8. (DOI: 10.15406/jnmr.2017.05.00110).

3. T. Joseph, P. Prakash, and S. S. Narvi. Phytofabrication and Characterization of Copper Nanoparticles using Allium sativum and its Antibacterial Activity, International Journal of Science Engineering and Technology, 2016, 4(2) 463472. (ISSN: 2348-4098).

4. S. Kumari, M. Venkatesham, D. Ayodhya, G. Veerabhadram. Green Synthesis, Characterization and Catalytic Activity of Palladium Nanoparticles by Xanthan gum. Applied Nanoscience, 2015, 5, 315-320. (DOI:10.1007/s13204-014-0320-7).

5. V. V. Makarov, A. J. Love, O. V. Sinitsyna, S. S. Makarova, I. V. Yaminsky, M. E. Taliansky, and N. O. Kalinina, Green Nanotechnologies: Synthesis of Metal Nanoparticles using Plants, Acta naturae, 2014, 6(1)20, 35-44.

6. G. Ingale and A. N. Chaudhari, Biogenic Synthesis of Nanoparticles and Potential Applications: An Eco-Friendly Approach, Journal of Nanomedicine \& Nanotechnology, 2013, 4(2), 1-7. (DOI: 10.4172/2157-7439.1000165). 
7. A. A. Lawrence, and A. J. T. Prakash, Biogenic Synthesis of Silver Nanoparticles using Manilkarahexandra(Roxb.) Dubard Stem Bark Extract and It's Physical, Chemical Characterization and Pharmaceutical Evaluation, International Journal of Applied Pharmaceutics, 2019, 11(3), 79-88. (ISSN:0975-7058).

8. H. Agarwal, S. V. Kumar, and R. S. Kumar, A Review on Green Synthesis of Zinc Oxide Nanoparticles An Ecofriendly Approach, Resource-Efficient Technologies, 2017, 3, 406-413, (DOI:10.1016/j.reffit.2017.03.002).

9. V. Sreenivasulu, N. S. Kumar, M. Suguna, M. Asif, E. H. Al- Ghurabi, Z. X. Huang, Z. Zhen, Biosynthesis of Silver Nanoparticles Using Mimosa pudica Plant Root Extract: Characterization, Antibacterial Activity and Eectrochemical Detection of Dopamine, International Journal of Electrochemical Science, 2016, 11, 9959-9971. (DOI:1020964/2016.12.69).

10. A. Shehzad, M. Qureshi, S. Jabeen, R. Ahmad, A. H. Alabdalall, M. A. Aljafary, and E. Al-Suhaimi, Synthesis, Characterization and Antibacterial Activity of Silver Nanoparticles Using Rhazya stricta, Journal for Life \& Environment Research, 2018, PeerJ, 6(e6086), 1-15. (DOI 10.7717/peerj.6086).

11. P. N. Padma, S. T. Banu, and S. C. Kumari, Studies on Green Synthesis of Copper Nanoparticles using Punicagranatum, Annual Research \& Review in Biology, 2018, 23(1), 1-10, (DOI: 10.9734/ARRB/2018/38894).

12. Azam, A. S. Ahmed, M. Ove, M. S. Khan, S. S. Habib, and A., Antimicrobial Activity of Metal Oxide Nanoparticles Against Gram-positive and Gram-negative bacteria: A Comparative Study, International Journal of Nanomedicine, 2012, 7, 6003-6009, (DOI:10.2147.IJN.S35347).

13. H. Kumar, M. and P. Sangwan, Synthesis and Characterization of $\mathrm{MnO}_{2}$ Nanoparticles using Co-precipitation Technique, International Journal of Chemistry and Chemical Engineering, 2013, 3(3), 55-160, (ISSN 2248-9924).

14. R. Mittu Synthesis, Characterization of Copper Nanoparticles - Review International Advanced Research Journal in Science Engineering and Technology. 2016, 3(5), 37-40. (ISSN 2393-8021).

15. M. Venkatesham, D. Ayodhya, A. Madhusudhan, N. V. Babu, and G. A. Veerabhadram, Novel Green One-Step Synthesis of Silver Nanoparticles using Chitosan: Catalytic Activity and Antimicrobial Studies, Applied Nanoscience. 2014, 4, 113-119, (DOI: 10.1007/s13204-012-0180y).

16. H. Katias, N. Z. Moden, C. S. Lim, T. Celesistinus, J. Y. Chan, P. Ganasan, S. S. I. Abdalla, Biosynthesis and Potential Applications of Silver and Gold Nanoparticles and Their Chitosan-Based Nanocomposites in Nanomedicine, Journal of Nanotechnology, 2018, 4290705, 1-13, (DOI: 10.1155/2018/4290705).

17. L. M. Madkour, Ecofriendly Green Biosynthesized of Metallic Nanoparticles: Bio-reduction Mechanism, Characterization and Pharmaceutical Applications in Biotechnology Industry, Global Drugs and Therapeutics, 2018, 3(1), 1-11, (ISSN: 2399-9098).

18. S. Sharma, D. Kau, S. Gupta, A. Singh, and K. Kaur, Antimicrobial Potential of Green Synthesized Gold Nanoparticles Against Human Pathogens, Acta Scientific Agriculture, 2018, 2(8), 145-152, (ISSN: 2581-365X).

19. P. Babji and V.L. Rao, Catalytic Reduction of 4-Nitrophenol to 4-Aminophenol by using $\mathrm{Fe}_{2} \mathrm{O}_{3}-\mathrm{Cu}_{2} \mathrm{O}-\mathrm{TiO}_{2} \mathrm{Nnanocomposite}$ International Journal of Chemical Studies, 2016, 4(5), 23-127, (E-ISSN 2321-4902).

20. H. Hassan, K. I. Omoniy, F. G. Okibe, A. A. Nuhu, and E. G. Echioba, Evaluation of Antibacterial Potential of Biosynthesized Plant Leave Extract Mediated Titanium Oxide Nanoparticles using, Hypheae Thiebeace and Anannos Seneglensis, Journal of Applied Science Environment Management, 2019, 23(10), 1795-1804, (ISSN 1119-8362).

21. T. Ahmed, M. Shahid, M. Noman, M. B. K. Niazi, F. Mahmood, I. Man zoor, Y. Zhang, B. Li, Y. Yang, C. Yan and J. Chen, Silver Nanoparticles Synthesized by using Bacillus cereus SZT1 Ameliorated the Damage of Bacterial Leaf Blight Pathogen in Rice, Pathogens, 2020, 9(160), 1-17, (DOI:103390/pathogens/9030160).

22. A. Narayanamma, Natural synthesis of Silver Nanoparticles by Banana Peel Extract and as an Antibacterial Agent, Journal of Polymer and Textile Engineering PT, 2016, 3(1), 17-25, (DOI: 10.9790/019X-03011725).

23. M. Jayandran, M. M. Haneefa, and V. Balasubramanian, Green synthesis and Characterization of Manganese Nanoparticles using Natural Plant Extracts and Its Evaluation of Antimicrobial Activity, Journal Pharmaceutical Science. 2015, 5(12), 105-110, (DOI:10.732/JAPS.2014.501218). 
24. X. Liu, C. Chen, Y. Zhao, B. Jia, A Review on The synthesis of Manganese Oxide Nanomaterials and Their Applications on Lithium-Ion Batteries, Journal of Nanomaterials, 2013, 736375, 1-7. (DOI:10.1155/2013/736375).

25. K. Pussi, J. Gallo, K. Ohara, E. Carbo-Argilbay, Y. Kolen'ko, B. Barbiellini, A. Bansil, S. Kamali, Structure of Manganes Oxide Nanoparticles Extracted via Pair Distribution Functions, Condensed matter, 2020, 5(19), 1-10, (DOI:10.3390/ condmat5010019).

26. M. Jayandran, M. M. Haneefa, V. Balasubramanian, Green Synthesis of Copper Nanoparticles using Natural Reducer and Stabilizer and an Evaluation of Antimicrobial Activity, Journal of Chemical and Pharmaceutical Research, 2015, 7(2), 251-259, (ISSN:0975-7384).

27. M. M. Haneefa, M. Jayandran, V. Balasubramanian, Evaluation of Antimicrobial Activity of Green-Synthesized Manganese Oxide Nanoparticles and Comparative Studies with Curcuminaniline Functionalized Nanoform, Asian Journal of Pharmaceutical and Clinical Research, 2017, 10(3), 347-352, (DOI: 10.22159/ajpcr.2017.v10i3.16246).

28. A. A. Kabria, Kamrunnessia, M.M. Rahman, A. Kar, Extarction and Evaluation of Phytochemicals of Banana Peels (Musa sapientum) and Banana Plants (Musa paradiasca), Malyaisan Journal Of Halal Research Journal, 2019, 2(1), 22-26, (DOI: 10.2478/mjhr-2019-0005).

29. J. J. P. Paul., M. Sakunthala, C. I. Udhaya, Green Synthesis of Manganese Nanoparticles using The Aqueous Extract of Ctenolepisgarcini (Burm. f.). International Journal of Botany Studies, 2017, 2(5), 7-75, (ISSN: 2455-541X).

30. G. Caroling, M. N. Priyadharshini, E. Vinodhini, A. M. Ranjitham, P. Shanthi, Biosynthesis of Copper Nanoparticles using Aqueous Guava Extract Characterization and Study of Antibacterial Effects, International Journal of Pharmacy and Biological Sciences, 2015, 5(2), 25-43, (e-ISSN: 2230-7605).

31. S. Pradhan, R. Shrestha, K. Bhandari, Effect of Various Parameters on Bio-Synthesis of Copper Nanoparticles using Citrus medica Linn (Lemon) Extract and Its Antibacterial Activity, Amrit Research Journal, 2020, 1(1), 51-58, (DOI:https://doi. org/10.3126/arj.v1i1.32454).

32. K. Jemal, B. V. Sandeep, S. S. Pola, Synthesis, Characterization, and Evaluation of The Antibacterial Activity of Allophylus serratus Leaf and Leaf Derived Callus Extracts Mediated Silver Nanoparticles, Journal of Nanomaterials, 2017, 4213275, 1-11, (DOI:10.1155/2017/4213275).

33. H. S. Kim, Y. S. Seo, K. Kim, J. W. Han, Y. Park, S. Cho, Concentration Effect of Reducing Agents on Green Synthesis of Gold Nanoparticles: Size, Morphology, and Growth Mechanism, Nanoscale Research Letters, 2016, 11(230), 1-9, (DOI :10.1186/s11671-016-1393-X).

34. S. Fatma, P. Kalainila, E. Ravindran, S. Renganathan, Green Synthesis of Copper Nanoparticle From PassiflorafoetidaLeaf Extract and Its Antibacterial Activity, Asian Journal of Pharmaceutical and Clinical Research., 2017, 10(4), 79-83, (DOI: 1022159/ajpcr.2017v10i4.15744).

35. S. P. Amatya, S. Shrestha, Bisynthesis of Manganese Nanoparticle (MnNPs) From Brassica oleraceae (Cabbage Leaves) and Its Antimicrobial Activity, Asian Journal of Chemical Sciences, 2021, 9(1), 1-11, (ISSN: 2456-7795).

36. V. Kumar, K. Singh, S. Panwar, and S. K. Mehta, Green Synthesis of Manganese Oxide Nanoparticles for The Electrochemical Sensing of p-Nitrophenol, International Nano Letter, 2017, 7, 123-131, (DOI 10.1007/s40089-0170205-3).

37. E. C. Shekhar, K. S. V. K. Rao, K. M. Rao, S. P. Kumar, A Green Approach to Synthesize Controllable Nanostructures From Lamoniaacidissima for Inactivation of Pathogenic Bacteria, Cogent Chemistry, 2016, 2(1144296), 1-14, (DOI:10 .1080/23312009.2016.1144296).

38. T. Kokila, P. S. Ramesh, D. Geetha, Biosynthesis of Silver Nanoparticles From Cavendish Banana Peel Extract and Its Antibacterial and Free Radical Scavenging Assay: A Novel Biological Approach, Applied Nanoscience, 2015, 5, 911-920, (DOI: 10.1007/s13204-015-0401-2).

39. H. M. M. Ibrahim, Green Synthesis and Characterization of Silver Nanoparticles using Banana Peel Extract and Their Antimicrobial Activity Against Representative Microorganisms, Journal of Radiation Research and Applied Sciences, 2015, 8, 265-275, (DOI: 0.1016/j.jrras.2015.01.007). 